\title{
Risk \\ The impact of Risk Identification on IT project delivery in Qatar Public Sector
}

Project risk management is the process of identifying, analyzing and the life cycle of a project to help the project remain on track and meet its goal

\section{Definition}

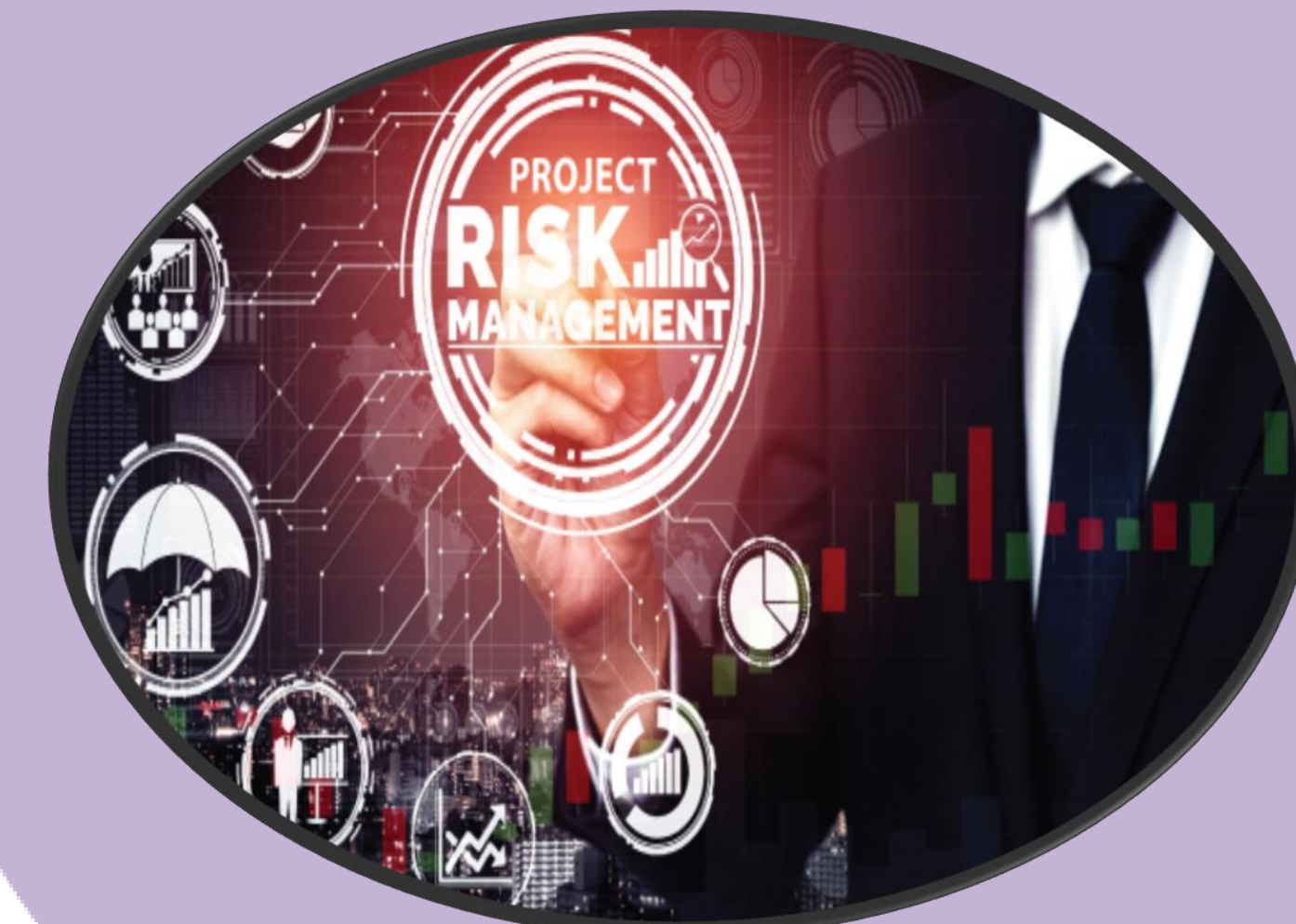
responding to any risk that arises over

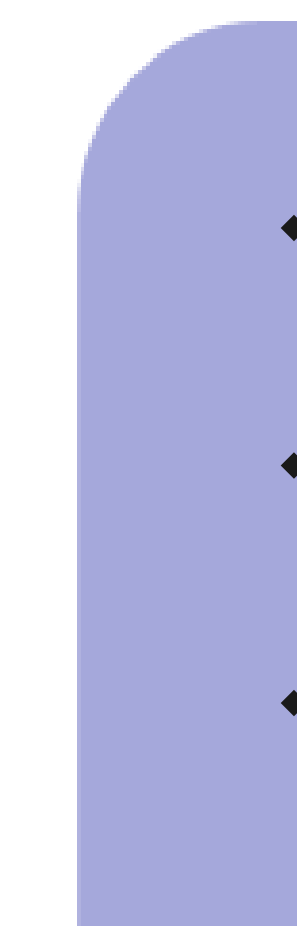

Better understanding of IT projec critical risk factors

- Enabling Project Managers to better manage project risks.

Decision makers better appreciate the value of risk management

\section{Benefits}
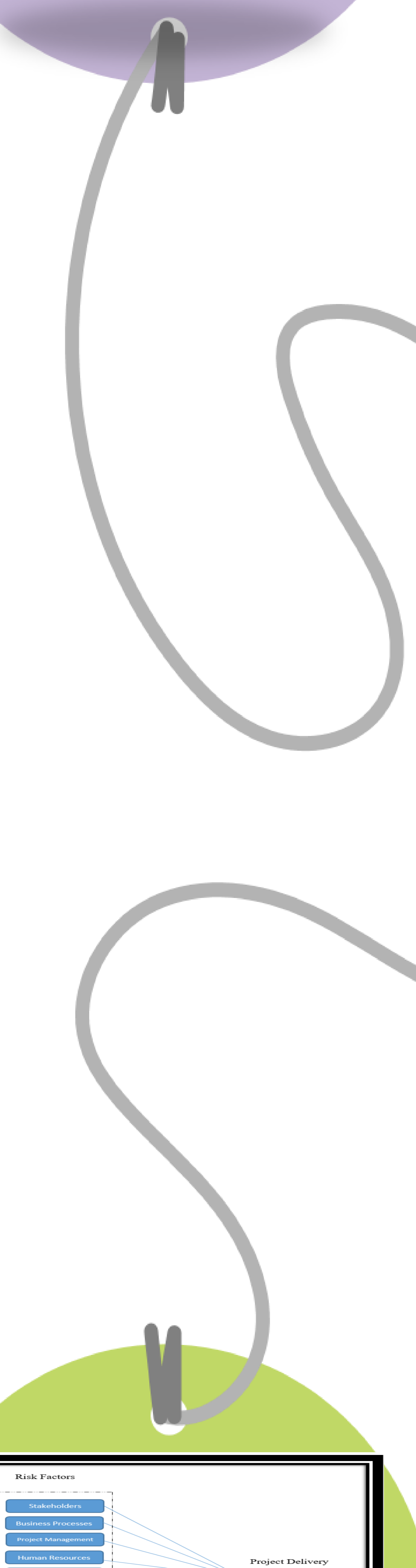

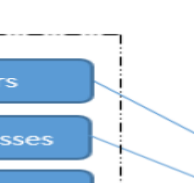
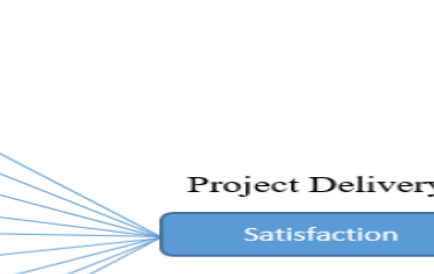

Method \& Model

* Online surveys (160 participants including PMs \& other project stakeholders)

* Research model (regression analysis)

* 9 hypotheses

* Instrument was reliable (Cronbach's alpha)

\section{Motivations}

* The research is aligned with Qatar vision 2030

* High rate of IT projects failure in IT projects within Qatar public secto

* The researcher being a PM in Qatar public sector
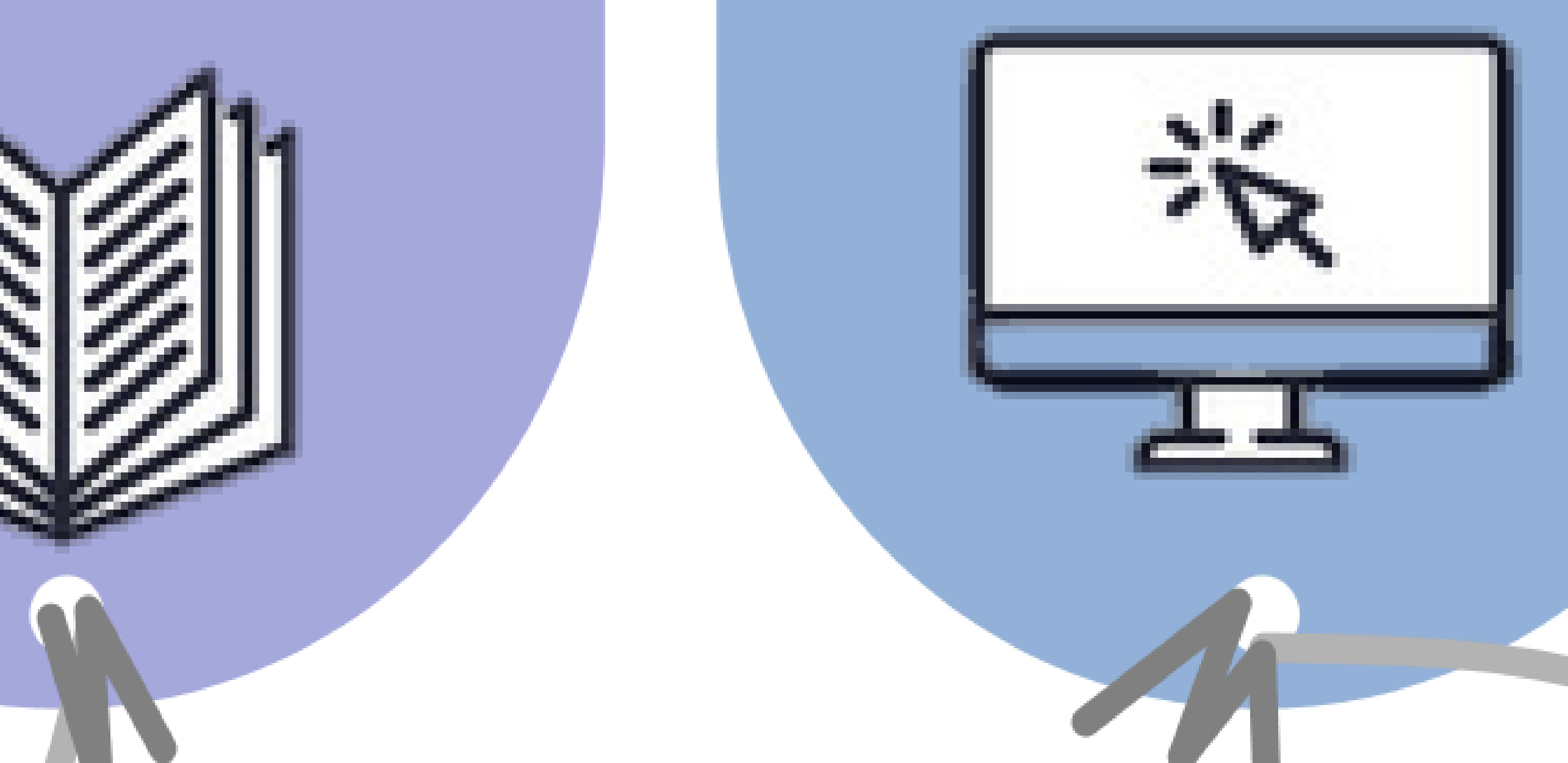

- Lack of research papers conducted
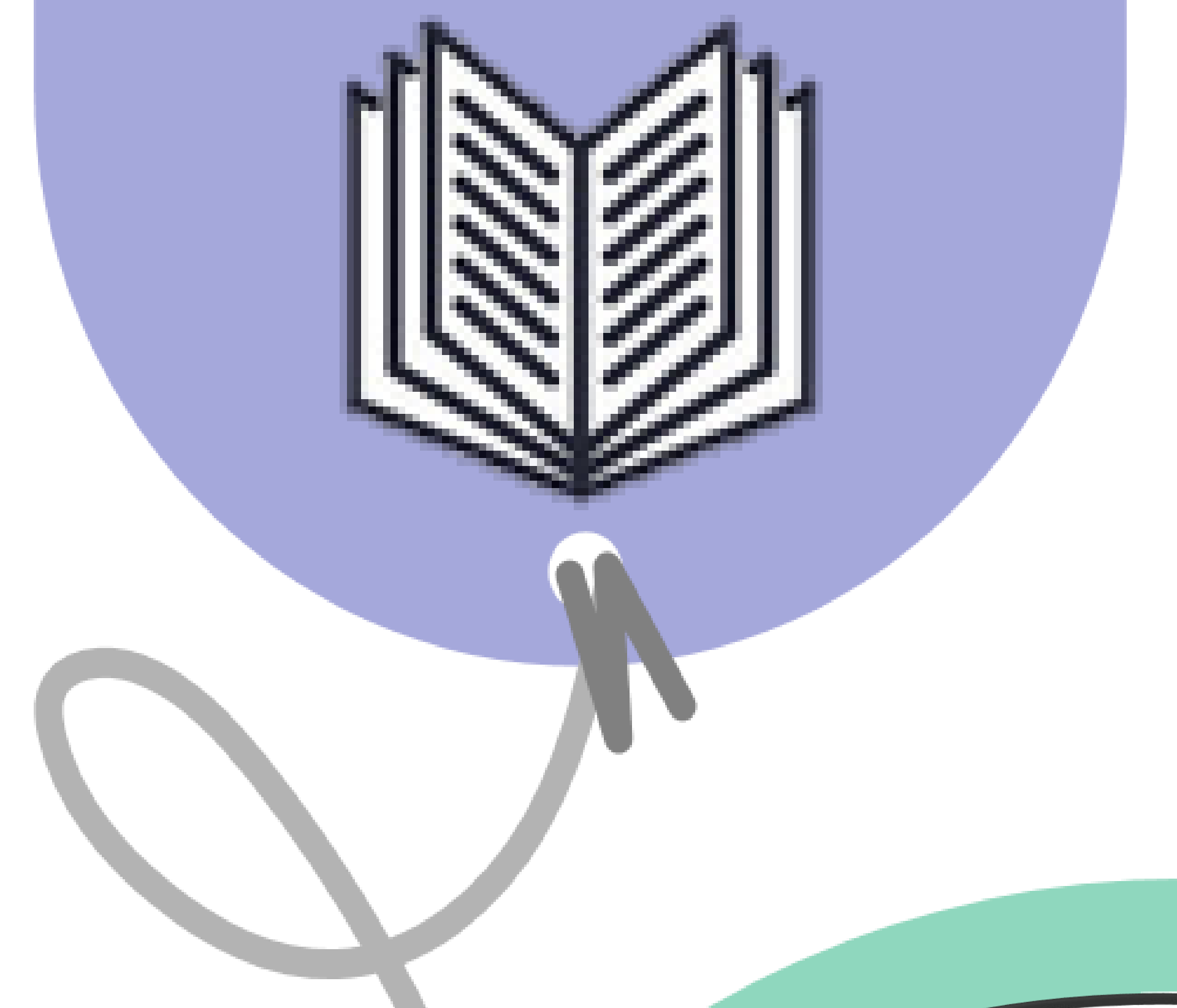

unication goals $\prod_{\text {PROJECT }}^{\text {analys }}$ risks MANAGEMENT budget

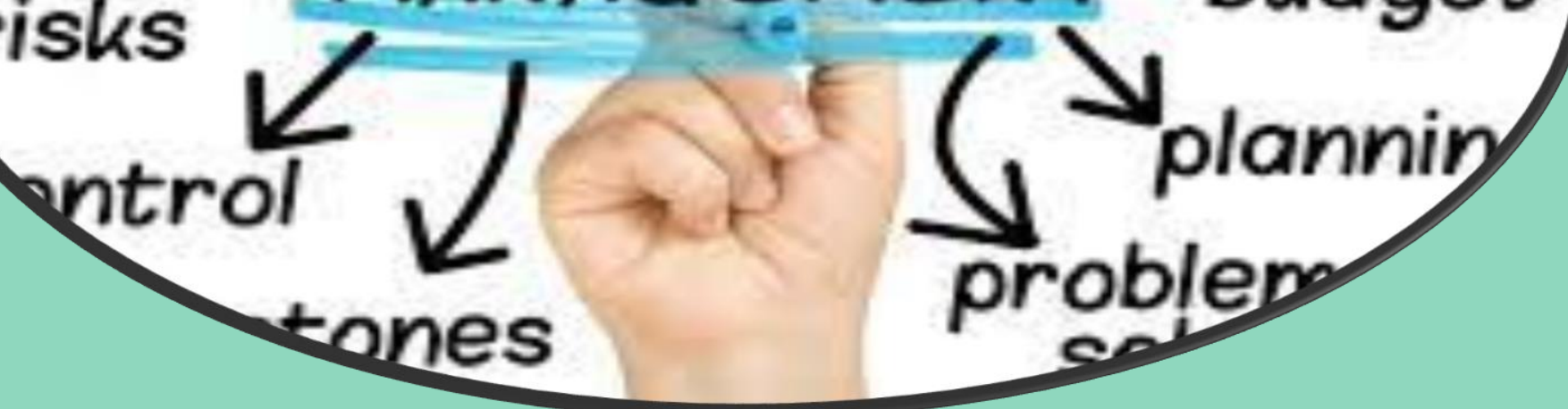

The impact of Risk Identification on IT project delivery in Qatar Public Sector eabushanab@qu.edu.qa Mutaz Oshi MBA Graduate -Qatar University moshi@qu.edu.qa

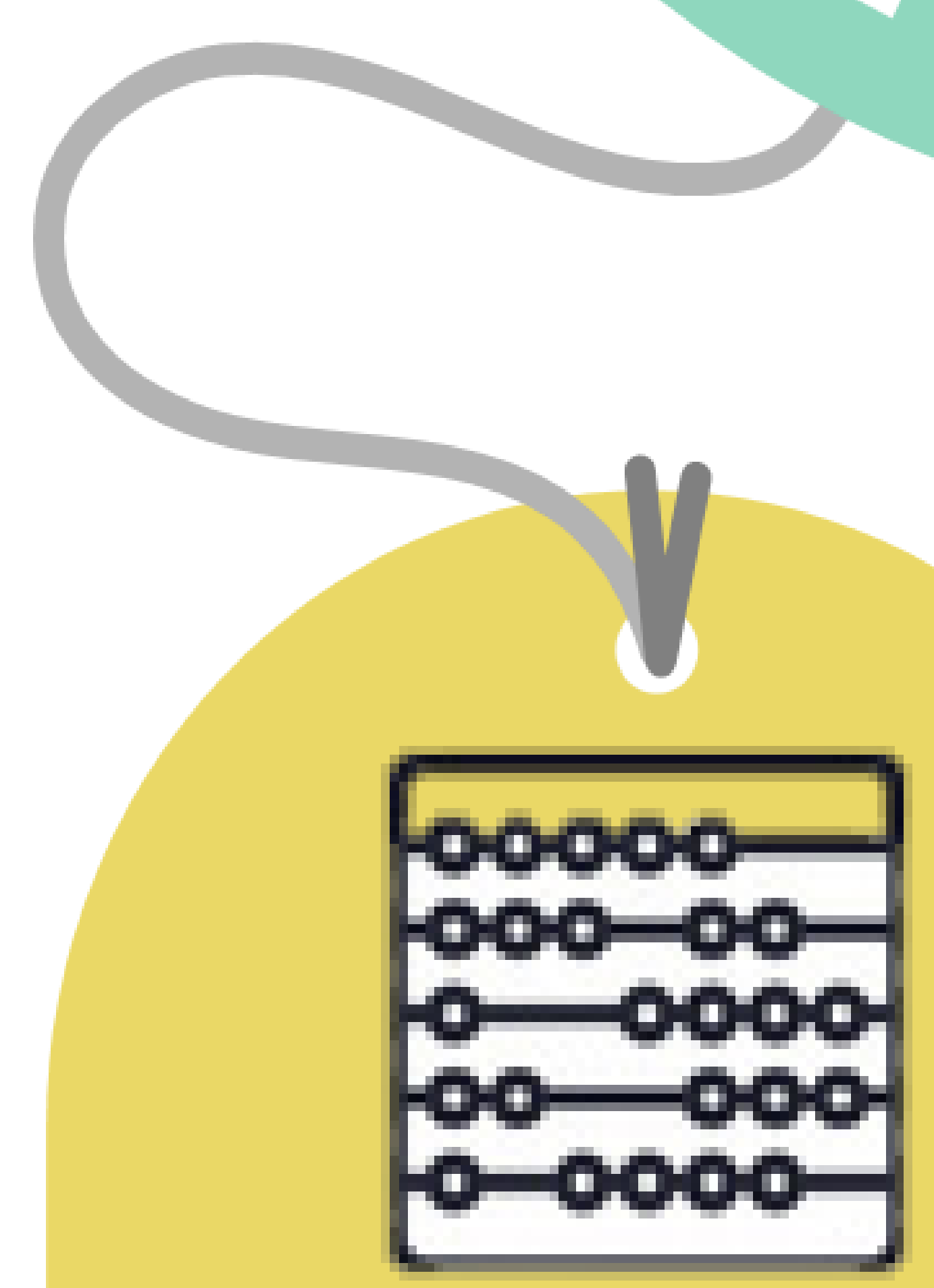

\section{Results}

Five Risk factors consistent with literature (Stakeholders, Business process, Organizational, Technical, and Schedule)

* Four Risk Factors inconsistent with literature (Project Management, Human resources, Budget, and External) CBE, A\&IS Dept. Qatar University

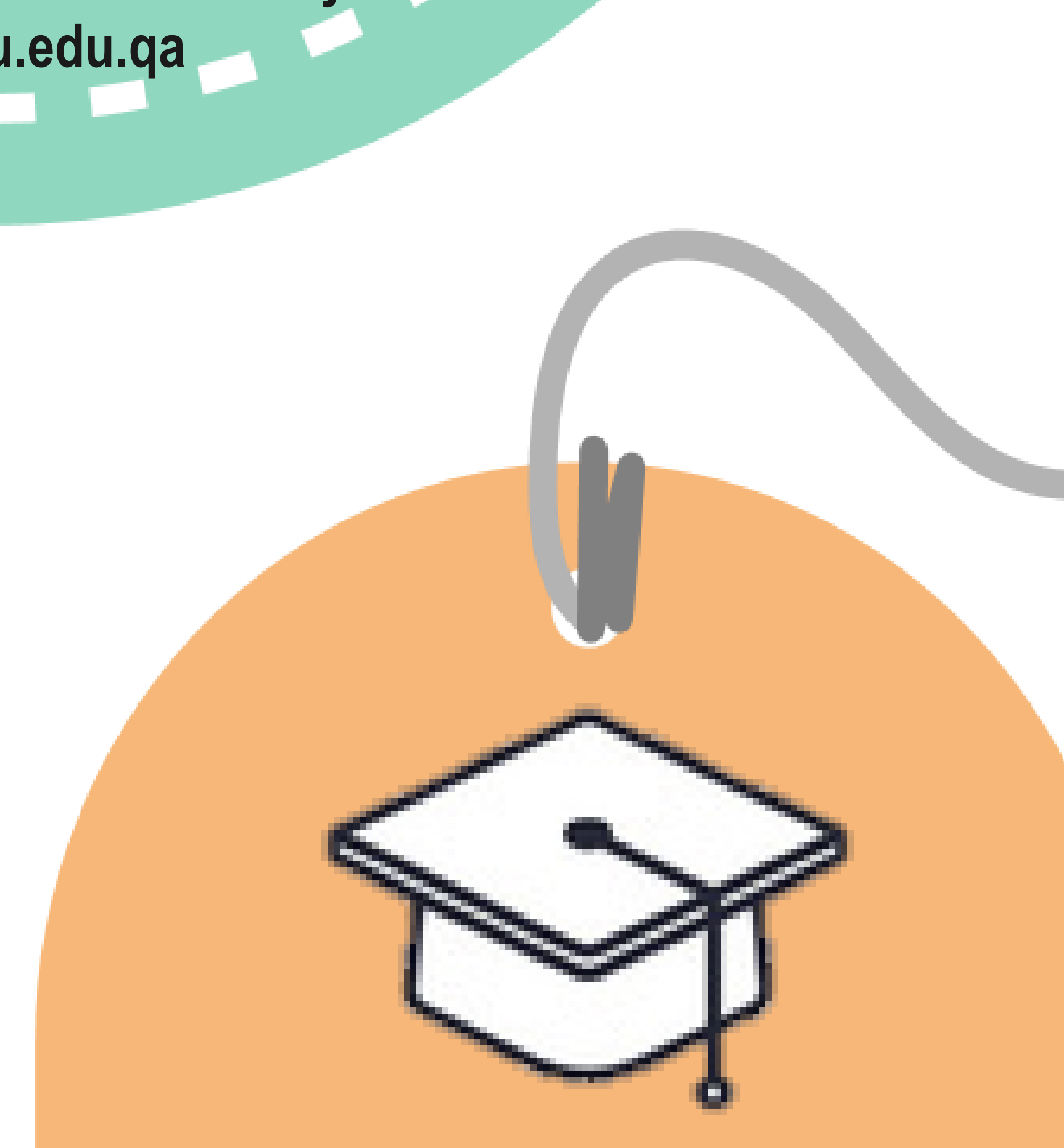

Conclusion

Out of 9 risk factors only 5 were identified

The identified risk factors positively impact IT project delivery

- Big data size might change the result and add more critical risk factors in Qatar public sectors context
What are the critical risk factors?

* What is the impact of each factor on project delivery?

What is the stakeholder's satisfaction with the identified factors?

\section{Research} Questions
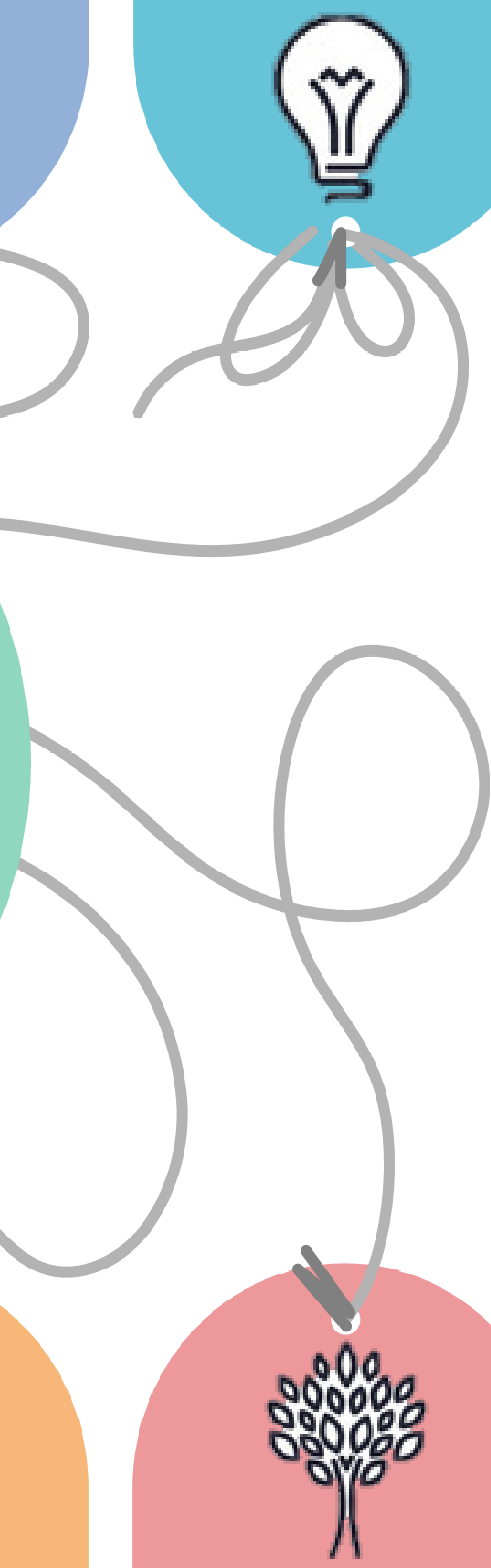

Implications

To the researcher's knowledge - first of its kind to be conducted in IT project delivery in Qatar public sector

- Qatar IT Private risk factors might revel different perspectives

- Need more support (instrument and model) 